\title{
PROCEEDINGS \\ OF THE ESTONIAN ACADEMY OF SCIENCES 50 Biology. Ecology
}

The science journal Eesti NSV Teaduste Akadeemia Toimetised (Proceedings of the Academy of Sciences of the Estonian SSR) was founded according to the Decree of the Presidium of the Academy of Sciences of 7 June 1950 (protocol No. 23). Initially it was planned as one journal for research papers produced at the Academy of Sciences covering a wide range of sciences. On 23 March 1949 the first editorial board of the Proceedings was approved by the Presidium of the Academy of Sciences. The executive editor H. Kruus, a historian, was nominated chairman of the board. Among the seven first members of the board R. Toomre was a specialist in the agricultural science and A. Reiman represented the medical science. Later, the editorial board was changed and G. Naan became chairman. The new board included also J. Eichfeld, a specialist in agricultural science. The publication of the Proceedings started in 1952.

The first issue presented the statement of the editorial board indicating the goals of the new scientific journal as follows:

- The Proceedings of the Academy of Sciences of the Estonian SSR is the publication of the Academy of Sciences.

- The Proceedings shall reflect the current scientific and organizational activities of the Academy.

- The Proceedings shall publish articles that introduce results of research work completed and information on most important research topics.

- The Proceedings shall give an overview of the general meetings of the Academy of Sciences, sessions of the departments, activities of the scientific councils of the research institutes, and the lectures delivered and discussions held in the institutions of the Academy.

- The Proceedings shall give information on the results of cooperation between research and production and application of scientific findings in practice.

- The chronicle section shall present information on current activities of the Academy.

- The Proceedings of the Academy of Sciences shall be published quarterly.

The first volume of the Proceedings carried signs of the historical period after Wold War II when much attention was paid to political interpretation of various sides of public life and social development under the newly established Soviet 
regime. Practically all the fields of science were politisized. This was true also about biology where the decisions of the notorious 1948 session of the All-Union Agricultural Academy were implemented, which determined the development of biological science and applications for decades. This is why the first volumes of the Proceedings in general and later the Biology series in particular seem now like science fiction.

The first issue of the Proceedings (1952) contained a paper on agricultural production and a review of the large-scale discussion on various problems connected with agricultural production in the postwar period. In the second issue a review on the scientific session held at the Institute of Experimental and Clinical Medicine was included. This institute was then in the system of the Academy of Sciences. Also a short review was dedicated to the problems of agricultural development on Estonian islands where the first collective farms were founded alongside the transition to the Soviet management system. Besides the predominating political aspects, some truly scientific problems connected with the specific natural conditions of the islands were discussed. Among the eight papers in the third issue of the 1952 volume three discussed various aspects of agricultural development. The fourth issue did not contain any papers on biology, medicine or agriculture but there was an 11-page review on the history and activities of the Tartu Naturalists' Society, one of the most important scientific associations in the Baltic area during a whole century since its foundation in Tartu in 1853.

From 1956 the Proceedings was published in three series: Engineering and Physical-Mathematical Sciences (chairman of the editorial board A. Humal), Biology (J. Eichfeld), and Social Sciences (G. Naan). In 1967 the fourth series was initiated: Chemistry. Geology. In 1978 this series was divided into two separate series: Chemistry and Geology.

Since 1990 the journal has the title, Proceedings of the Estonian Academy of Sciences. In 1991 a new series, the sixth under the Proceedings, Ecology, was founded. This was the first series with all contributions in the English language. In 1997 this series was joined with the Biology series and now it is entitled Biology. Ecology.

Chairmen of the Biology, Ecology, and Biology. Ecology series have, as a rule, been members of the Estonian Academy of Sciences:
1956-59 J. Eichfeld (Biology);
1960-86 H. Haberman (Biology);
1987-91 E. Parmasto (Biology);
1991-96 J. Martin (Ecology and Biology series joint editorial board);
1997-2001 J. Martin (Biology. Ecology);
2001- U. Margna (Biology. Ecology).

In the first period the Biology series published research and review papers on general biology from different fields of the discipline (mainly zoology and botany), soil science, etc., medical science, including veterinary medicine, agriculture, and forestry. Every issue contained also reviews of the most important scientific meetings in the listed fields, a chronicle, and personalia. Papers were 
mostly written in Estonian or Russian with German or English summaries. Starting from 1957, as an Appendix a bibliography of the publications of employees of the institutions of the Academy of Sciences conducting research in biology was published.

In general, the first period of the Biology series publications reflected the main trends in biological research after World War II. About half of the papers on biology contained information on the flora, fauna, and field expeditions in Estonia to continue the inventory of nature complexes interrupted during the war. Another part of the publications, about $40 \%$ of the total number of articles, had an applied direction, discussing practical aspects of the development of agriculture (crop selection and productivity, impact of drainage, reforestation, etc.) and experimental research that served the needs of agriculture. Some attention was paid to nature protection. For example, in 1958 a detailed plan for the development of the botanical garden (officially founded in 1961) as a separate research institution in the system of the Academy of Sciences was published.

During the following decades the Biology series served as a main publication of the research results in a wide area of biology for the scientific institutions of the Academy of Sciences: Institute of Zoology and Botany, Institute of Experimental Biology, and Tallinn Botanical Garden. The role of research papers from universities was considerably small. Tartu State University and the Estonian Agricultural Academy, as well as applied research institutions under different ministries (Institute of Experimental and Clinical Medicine, Institute of Agriculture and Land Amelioration, Institute of Nature Protection and Forestry, etc.) had their own publication series.

The Ecology series, established considering the growing interest in nature and environment and international cooperation, existed unfortunately only for six years. Approximately a hundred articles were published during this period. Most of the authors of the research papers were from the newly founded Institute of Ecology, Estonian Marine Institute (at first as a department of the Institute of Ecology, later a separate research institute at the Ministry of Environment), and Tallinn Botanical Garden. The main fields covered by the Ecology series were marine research (more than a third of the publications), hydrochemisry and limnology, forest ecology, lichen ecology, and ecophysiology. It should be mentioned that Ecology published several papers written by foreign authors and from the very beginning some experts from abroad were invited as members of the editorial board.

In the same period Biology published a little more than a hundred papers. Among these, articles on entomology, ichthyology, hydrobiology, plant biochemistry and genetics, and also applied plant science predominated. Most of the research papers were presented by researchers from the Institute of Zoology and Botany, Institute of Experimental Biology, Tallinn Botanical Garden, and the Estonian Agricultural University.

After the restoration of independence, rapid changes started also in science. During several years most of the research institutes were joined to universities. 
This reorganization and introduction of new criteria for the evaluation of the results of scientific work by financing agencies resulted in a decrease in the number of research papers submitted for publication to both Ecology and Biology series. As a result, the two series were joined into one.

As a positive trend, cooperation with university researchers has increased during the last five years. As the Institute of Zoology and Botany is now a separate institution at the Estonian Agricultural University, the number of articles from this university reached approximately half of the total number. The publications dealing with marine research, hydrology, hydrochemistry, limnology, hydrobiology, and ichthyology constitute also about a half of the publications. These have been presented mainly by the Estonian Marine Institute (presently a research institute of the University of Tartu) and the Institute of Ecology (now at Tallinn Pedagogical University).

A new practice, which supports dissemination of information as well as increases the impact of the series, is the publication of conference contributions in special issues. For example, a collection of papers on Lake Peipsi (Vol. 49, 1) and on the history of the marine and freshwater research around the Baltic Sea (Vol. 49, 4) have appeared. Starting from 1997 the contents and from Volume 49 also abstracts of publications are available via the Internet. This will hopefully have a favourable influence on the reputation of the journal.

Jüri MARTIN

Chairman of the Editorial Board

(1991-2001) 